as much aneurin as is needed. Such yeast can also be obtained in tablet form. (c) Autolysed yeast is best, because only about $20 \%$ of the vitamins are available in live yeast. The best plan is to pour boiling water on the yeast to kill the cells before it is eaten. $(d)$ Yeast bought at the local baker's is unsatisfactory as a source of B vitamins, as it is of unknown potency. Thus the aneurin content may vary from 0.03 to $2 \mathrm{mg}$. per ounce. For the same reason home-made yeast is unsatisfactory. Incidentally yeast cannot be prepared by the method described, which would encourage the growth of many moulds and organisms. (e) From the point of view of absorp.ion of the vitamins, it does not matter whether yeast is taken with meals or not.

\section{Removal of Naevus}

Q. - My daughter, aged 11 months, has a naevus about the size of a sixpence on her forehead at the junction of hair and skin. It is slightly raised and rather disfiguring. What is the best treatment?

A.- The naevus would appear to be a superficial cavernous angioma, a strawberry mark, and is likely to disappear spontaneously in the course of a few years. It should readily clear if frozen with a pencil of carbon-dioxide snow for twenty seconds. Unfiltered $x$ rays, $600 \mathrm{r}$ units $(60 \mathrm{kV}, 4 \mathrm{~mA})$, would also favour gradual resolution, and neither treatment should produce scarring to interfere with hair growth.

\section{Irregular Menstruation}

Q.-Is it possible to use stilboestrol in the case of a woman nearing the menopause whose periods are becoming irregular? If so, what is the optimum dosage, and would prolonged administration be dangerous? Is there any risk if the delay is due to pregnancy?

A. - If the only "menopausal" symptom is irregularity of menstruation, treatment with stilboestrol or other oestrogens is rarely, if ever, indicated. If the irregularity takes the form of periods of amenorrhoea; no attempt should be made to reestablish menstruation; whereas if it is characterized by prolonged or heavy bleeding. diagnostic curettage should be carried out. The only possible indication is in those cases where prolonged bleeding has been shown (by histological examination of the endometrium) to be of the "threshold" type. The indiscriminate and prolonged use of stilboestrol at the menopause has real disadvantages. Unless the dose is controlled very carefully it is likely to cause endometrial hyperplasia and heavy bleeding, and in theory at any rate might cause carcinoma of the uterus. Moreover, if such treatment is suspended suddenly, flushes and other manifestations of the menopause may be precipitated. Stilboestrol even in large doses will not disturb a normal pregnancy.

\section{Mixed Diphtheria Toxoid and Pertussis Vaccine}

Q.-In inoculation with mixed diphtheria A.P.T. and pertussis vaccine (alum-precipitated) it is recommended that three injections be given at intervals of four weeks. When the patient is not brought up to time, should one anticipate any severe reaction, and is protection adequate with a longer interval between the first and second injections? If a fresh course should be started, what interval should elapse between the first injection of the new course and the first injection of the abandoned course?

A.- It has been well established experimentally that in immunization against diphtheria with A.P.T. the second injection, even if it is given six to twelve months after the first injection, will still elicit a good antibody reaction provided the first dose has been adequate to sensitize or prepare the tissues for response to the secondary stimulus. The risk of any severe reaction is not increased by a long interval between first and second doses, but of course if the second injection is delayed unduly the child in the meantime cannot be regarded as having been effectively immunized against diphtheria. The same principles presumably apply to the use of a mixed antigen of diphtheria toxoid and pertussis vaccine; there is no objection to combining these two antigens, provided each has been shown to be effective separately.

\section{NOTES AND COMMENTS}

Enuresis in Young Adults. - Mr. H. P. Winsbury-White (London, W) writes: In the Journal of Dec. 20, 1947 (p. 1016), a question is asked in these words: "Can anything be done to benefit chronic enuresis in young adults? In the case I have in mind full neurological and urological examinations have proved negative." The points of fundamental importance in this matter are that what is called a full urological examination commonly omits a urethroscopy, 흐 and that young adults with enuresis frequently have a lesion in the $\bar{c}$ urethra, and the appropriate treatment of such a lesion generall $\underset{\mathbb{D}}{\vec{Q}}$ results in a marked improvement or a cure of the enuresis. Let me $\varrho$ recount the facts of a recent case, a male of 19 years.

At the age of 14 he started bed-wetting two or three times a week " $c$ and had one-hourly frequency during the day. At the age of $16, \overrightarrow{0}$ a full urological examination, which included urethroscopy, had $\rightarrow$ been carried out, when the only abnormalities to be found were $\vec{\omega}$ granulomatous changes on the verumontanum and in the prostatic o. sinuses, and there was slight narrowing of the whole urethra. As a result of a single urethral dilatation the patient had only two we beds in the course of the first three months after this treatment.. Then he went for the next twelve months without a single wet bed : no further treatment was given during that time. He then began to relapse slowly and further urethral dilatations did not help him. Urethroscopy at the age of 19 showed granulomata still present as $\vec{\omega}$ before. These I fulgurated two months ago, with immediate benefit, $A$ the frequency being reduced from one to three hours, and the $\delta$ enuresis to no more than three occasions in five weeks: whereas. previous to operation he had been having one or two wet beds every week.

The benefit to the patient's mental state from the improvement $c$ he again experienced was certainly a gratifying and interesting feature of the case. This patient will certainly need further supervision and probably more treatment, in which circumstances I consider the prospects good.

\section{Corrections}

In our report (Dec. 27, p. 1049) of a meeting of the Section of Otology of the Royal Society of Medicine, the statement " $\mathrm{Mr}$. Gavin Young said that formerly cases of acute mastoiditis were met with once or twice a year," should have read "cases of latent acute mastoiditis."

In reporting a meeting of the Section of Psychiatry of the Royal Society of Medicine (Dec. 27, p. 1048) some remarks made by the previous speaker were erroneously attributed to Dr. Melanie Klein. 3 What Dr. Klein actually said was: "In considering the importance of aggression in the emotional life of the infant, we have to give full weight to the fact that aggression, since it is primarily directed against loved people-first of all the mother-gives rise to feelings of guilt and to the drive to make reparation. The tendency to make reparation enters into all sublimations and influences feelings of love and the relation to people. In these ways aggression forms a bridge $\frac{0}{3}$ between hatred and love. Freud pointed out many years ago the importance of the sublimation of aggression and the social effects of 8 these processes. Further work, particularly carried out in the British Psycho-Analytical Society over the last twenty years and based on the psycho-analysis of children, has led to the recognition of the, importance of the tendency to make reparation for aggressive $N$ impulses and phantasies."

In our obituary notice of the late Mr. G. F. Stebbing (Jan. 3, I p. 28) it was stated that he had been " a member and honorary secretary of the Radium Commission from its formation in 1929." N We are now informed that this was not the case. Prof. Sidney Russ $N$ was Scientific Secretary of the National Radium Commission from $\omega$ 1929 until 1935.

Dr. R. T. BraIN points out that in his note on "Ringworm of Scalp" (Jan. 10, p. 86) thorium $X$ was written in error for thallium $\mathbb{D}$ acetate.

All communications with regard to editorial business should be addressed to THE EDITOR, BRITISH MEDICAL JOURNAL, B.M.A. HOUSE, TAVISTOCK SOUARE, LONDON, W.C.1. TElePHONE: EUSTON 2111. TElegrams: Aitiology, Westcent, London. ORIGINAL ARTICLES AND LETTERS forwarded for publication are understood to be offered to the British Medical Journal alone unless the contrary be stated.

Authors desiring REPRINTS should communicate with the Publishing Manager B.M A House. Tavistock Square. W.C.1, on receipt of proofs. Authors. ? B.Meas if reprints are required, as proofs are not sent abroad.

ADVERTISEMENTS should be addressed to the Advertisement Manager. B.M.A. House, Tavistock Square, London, W.C.1 (hours 9 a.m. to 5 p.m.). B.M.A. House, Tavistock Square, London, W.C.1 (hours 9 a.m. to 5 p.m.). TEMBRS : EUSTORIPTIONS ThOUId be sent MEMBERS' SUBSCRIPTIONS should be sent to the SECRETARY of the TELEGRARS: Medisecra, Wevtcent. London.

B.M.A. SCottish Office: 7, Drumsheugh Gardens, Edinburgh. 